\title{
Public Perceptions of MSW Management in Wrocław City, Poland
}

\author{
Anas Zyadin 1,2*, Karthikeyan Natarajan"1,2, Suvi Kuittinen 1,2, Tanja Kähkönen1,2, \\ Bartłomiej Igliński³ ${ }^{3}$ Magdalena Dąbrowska ${ }^{4}$, Maxim Trishkin ${ }^{1,5}$, Ari Pappinen' \\ ${ }^{1}$ University of Eastern Finland (UEF), Joensuu Campus, Joensuu, Finland \\ ${ }^{2}$ Institute of Natural Resources, Environment and Society (LYY), University of Eastern Finland (UEF), Joensuu, Finland \\ ${ }^{3}$ Nicolaus Copernicus University in Toruń, Torun, Poland \\ ${ }^{4}$ Faculty of Production Engineering, Warsaw University of Life Sciences, Warsaw, Poland \\ ${ }^{5}$ Pöyry Management Consulting, Vantaa, Finland \\ Email: ^anas.zyadin@uef.fi, *anas.zyadin@gmail.com, karthikeyan.natarajan@uef.fi, suvi.kuittinen@uef.fi, \\ tanja.kahkonen@uef.fi, maxim.trishkin@uef.fi, ari.pappinen@uef.fi, iglinski@chem.umk.pl,magdalena_dabrowska@sggw.pl
}

How to cite this paper: Zyadin, A., Natarajan, K., Kuittinen, S., Kähkönen, T., Igliński, B., Dąbrowska, M., Trishkin, M. and Pappinen, A. (2020) Public Perceptions of MSW Management in Wrocław City, Poland. Journal of Sustainable Bioenergy Systems, 10, 16-29.

https://doi.org/10.4236/jsbs.2020.101002

Received: January 22, 2020

Accepted: February 28, 2020

Published: March 2, 2020

Copyright $\odot 2020$ by author(s) and Scientific Research Publishing Inc. This work is licensed under the Creative Commons Attribution International License (CC BY 4.0).

http://creativecommons.org/licenses/by/4.0/

\begin{abstract}
Elevating public awareness of waste management at the household level is a cost effective and a win-win social, economic and environmental approach on the table of policymaking. Modern and effective waste management bring about broader economic efficiency and social equity, mitigate consumerism, thus, promoting the conservation of natural resources. In this article, a survey study was conducted among the citizens of Wrocław city, Poland. The city is dynamic, touristic, and industrial. Through random sampling, 160 respondents filled in the questionnaire. The results revealed that the participants appeared aware of the benefits of waste management (WM); however the current WM systems and infrastructures are not very satisfying. The participants identified several shortcomings in the current WM systems such as the lack of sufficient colored bins for glass recycling, overfilled bins and heavy lids, and irregular waste collection system. The study proposes a public-oriented outreach campaign targeting waste separation and less-waste behaviors as economically and environmentally beneficial, accompanied by continuous development of WM regulations and infrastructures and linked it to waste-to-energy systems and technologies to assist in achieving the long-term energy and emissions-reduction targets.
\end{abstract}

\section{Keywords}

Waste Management, Poland, Wrocław City, Perceptions

\section{Introduction}

The global population is rapidly growing so as the associated household and in- 
dustrial wastes. New patterns of lifestyle characterized by high-consumption behaviors, stemmed mainly from higher per capita income, have substantially increased quantities of Municipal Solid Wastes (MSW) of which Household Solid Wastes (HSW) contribute about 75\% [1]. As an example, the three North American countries Canada, the US, and Mexico altogether generate nearly 265 million tons of organic waste annually [2] of which approximately 75 million tons are diverted to industrial-scale composting activities and the remaining 190 million tons are disposed in landfills. In India, studies calculated that India's MSW stands at 68 million tons per year or about 188 thousand tons per day [3]. Beijing, the capital city of China, was estimated to produce over 7 million tons of wastes annually with a forecasted increase at $8 \%-10 \%$ annually [4]. In the EU-28-member states, $487 \mathrm{~kg}$ of municipal waste per capita were generated in the EU in 2017. Moreover, the amount of municipal waste incinerated has risen 105\% accounted for 66 million tons in 2016 [5]. Depending on how wastes are treated and the wealth of people, the per capita waste generation varies in the EU-28 states ranging from $777 \mathrm{~kg}$ per capita in Denmark to $261 \mathrm{~kg}$ per capita in Romania [5].

Improving the MSW management's pillars including, inter alia, collection, reuse, recycling and segregation, indeed, requires a combination of cutting-edge technology (e.g. Polyethylene Terephthalate (PET) downgrading) and efficient infrastructures, operational cost-efficiency in cities waste separation and collection. Another cost-effective yet quintessential approach involves reducing household waste generation through improving public awareness of waste separation, recycling, and reuse attitudes. In doing so, the potential socio-economic benefits are numerous in terms of job creation, increase per capita GDP, and improve the environment and living conditions in cities [2]. Moreover, reducing volumes of HSW through fiscal/financial support schemes deemed a convenient approach to local authorities [1]. On this pretext, economic instruments such as collection service fees along with automated processing and sorting technology have been developed, commercialized, and implemented in many developed countries [6]. Moreover, waste management (WM) activities are among the cost-effective solutions to save natural resources, reduce waste treatment and landfilling costs, and bring about broader economic efficiency and social equity, mitigate consumerism, thus, promoting environmental conservation [7].

Much of nowadays scientific efforts focus mainly on technological innovations or economic instruments yet oversight of a broader holistic and inclusive social approach to include latent psychological constructs such as citizens' values, beliefs, and attitudes toward e.g. protecting and preserving the environment through informed conscious and awareness of environmental phenomena.

Therefore, the confluence of public awareness, acceptance and support for proposed measures to e.g. cut emissions through curtailments in energy use and waste production, and by clean energy adoption and deployment has inherently been acknowledged within the scientific arena [8]-[13]. These studies revealed a 
relationship between a number of socio-economic and demographic factors such as age, gender, home type, political orientation, cultural context, income and educational level and the individual's propensity to possess environmentally friendly behaviors such as energy saving [14].

For example, in Canada, food and waste awareness, family lifestyles, and convenience lifestyles were related to food waste production [7]. In Denmark, food waste generation was influenced significantly by household size and the housing type [15] whilst in Finland food waste was reduced due to less food being prepared from scratch accompanied by environmentally conscious citizens. In many Middle Eastern countries, food waste and mixed wastes generally triple in religious holidays due to societal norms of celebrating [16]. Higher educational attainments appeared positively corrected with waste management whilst higher income tends to increase the household waste generation in developing countries. In some cases, young people tend to generate more waste than elderly people [17]. Moreover, in developing countries waste generation and/minimization appeared explicitly linked to household income level. In Dhaka city of Bangladesh, a highly populated city, Ref. [18] found that household waste generation is significantly affected by middle-class income level, age group, and level of environmental consciousness. Income was also reported as socio-economic factor in waste generation in Nigeria [19]. Similar results were reported in Sri Lanka were household income, household size, and number of employed family members highly affect waste generation, especially food and packaged items [20]. Similar study was conducted in Colombo Municipal Council of Sri Lanka where private sector handles $65 \%$ of waste management [21]. The survey study revealed an overall public satisfaction (67\%) with the current WM system however $78 \%$ of the participants appeared unwilling to pay for value-added services and the majority appreciate daily collection of waste and that segregation bins are provided at no additional costs [21]. The study also referred to the double waste collection process as inefficient (curbside to handcarts to secondary collection point), and vandalism of public waste bins as a challenge to WM. Ref. [22] carried out a survey study in the City of Laramie in Wyoming, the USA and found that over $80 \%$ of the respondents referred to environmental concern as a key motive for recycling followed by the convenience of city's curbside recycling program (66\%). The study also linked the respondents recycling knowledge an environmental concern to their level of education. Other studies have also found a link between demographic and socio-economic factors such as gender, age, income level, and education attainment affecting the community recycling attitudes and behaviors [22] [23] [24].

Poland is a southern European country and considered to be the ninth-largest European country with a population of slightly above 38 million-counting for nearly one-tenth of the European Union's (EU) population. Like many other European countries, strategic planning and future targets have also been set for reducing landfilling of MSW in Poland. The Polish Waste Prevention Pro- 
gramme was adopted by the Council of Ministers on 26 June 2014-with total budget 22.79 million euros. The programme prioritizes waste types according to the following criteria: waste that has a considerable share in the total quantity of annually generated waste, waste that has a considerable share of hazardous waste specifically chemical industry waste, and waste for which prevention options already exist, for example municipal waste, packaging waste, and food waste [25]. The National Waste Prevention Programme and the Waste Act aims to maintain a constant quantity of waste and to reduce the waste generated based on the Gross Domestic Product (GDP). Of key importance is the objective to reduce food waste, mining waste, and waste arising from thermal processes compared to energy generated [26] (National Waste Prevention Programme, 2014). It is estimated that the country generated 130 million tons of industrial wastes (coal mining) and 12 million tons of MSW in 2010 [5].

In 2014, average waste per capita waste per generation per year was $272 \mathrm{~kg}$ (Figure 1).

In 2007-2008, the government increased landfill taxes and as a result recycling of waste materials has increased from 5\% of MSW generated in 2004 to $21 \%$ in 2010. Moreover, landfilling dropped from $74 \%$ in 2007 to about $60 \%$ in 2010 (Eurostat, 2012) [5]. The population of Wrocław in 2016 was 637,075 making it the fourth-largest city in Poland. It is an attractive tourist destination but also accommodate large industrial agglomerations.

The overall aim of the study is to investigate how the public in Wrockaw perceive the current MSW management system, and what is needed to improve the system, and to which extent they perceive the waste-to-energy concept, especially the use of wastes in power plants to generate electricity and heat. For that reason, a survey-based study was conducted in Wrocław city and the results are presented in this article. The first section of the article deals with the public perceptions of MSW, the second provide waste quantification (quantitative), and the last part is dedicated to present and discuss the participants' freely expressed opinions (qualitative).

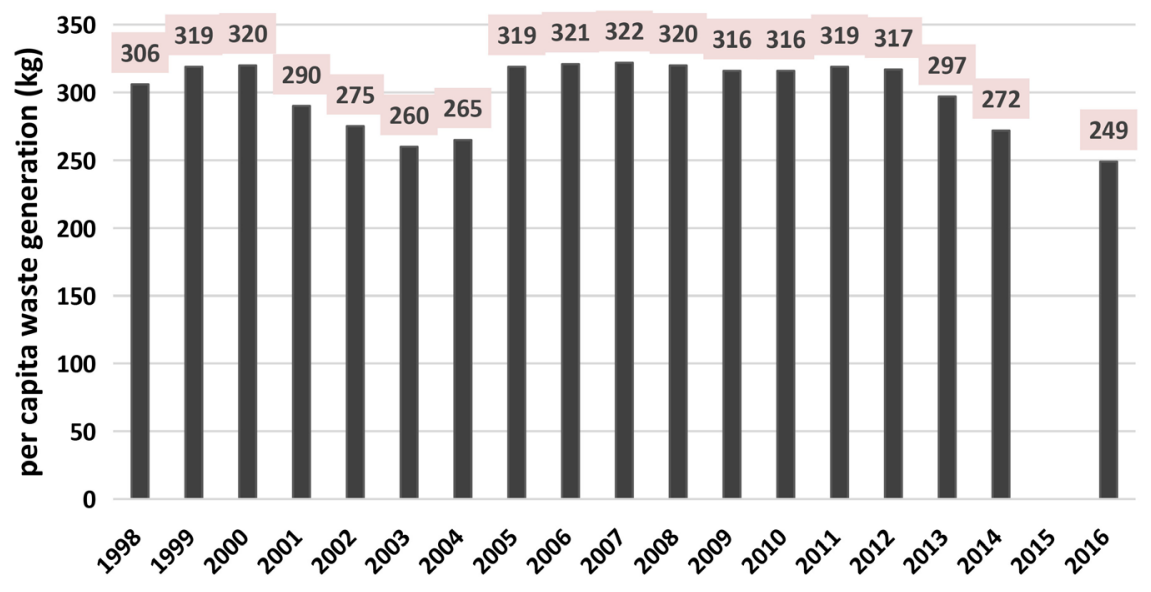

Figure 1. Per capita waste generation in Poland per year (1998-2016). 


\section{Survey Data}

The data was collected through self-instructed questionnaire over a period of 3 months (June-August) in 2017. The authors of this study participated in designing the questionnaire based on thorough analysis of the MSW situation in Poland and literature review. The questionnaire consisted of seven sections each with an objective. The questionnaire was designed first in English language and later on was translated into Polish language. A cover letter accompanied the questionnaire to get the participants acquainted with the study aims. The message was "the government of Poland seek to reduce the amount of municipal solid waste (MSW) going to landfill by $50 \%$ to meet the EU standards. One of the key measures is to reduce mixed household wastes and encourage waste separation in order to use it for energy generation. In this survey, we would like to know how much waste being separated in your home and what measures are needed to promote household waste separation".

Section one dealt with household socio-economic and demographics such as age, gender, home type and size, education level, years living in the city, occupation, and yearly family income (optional). Section two had a series of various types of questions such as (yes/no), scale, and data to be filled. Here, the participants were asked whether they have different containers/bags for waste separation at home, how much they pay for waste collection, and whether they get incentives for doing so. The source of information was investigated by presenting seven different information sources such as traditional mass media with scale of answers related to regularity: regular, sometimes, infrequently, and never. Section three was dedicated to quantifying waste generation and also separation, mixing, and reusing quantities and their percentages for cartons (tetra packs), paper, plastics, metals, and glasses. Section four dealt with regularity of waste separation: how often the items are being separated with answers as follow: regular, sometimes, infrequently, and never. Section five was dedicated to investigating public perceptions, attitudes and beliefs toward waste separation and through nine statements. Here we used 5-Likert scale type (strongly agree, agree, I don't know, disagree, and strongly disagree). Motives/needs to encourage waste separation at the household' level was tested through six statements in section six using 5-Likert scale type (strongly agree, agree, I don't know, disagree, and strongly disagree) as in section five. For the results presentation, we combined strongly agree plus agree into "strongly agree" and strongly disagree plus disagree in into "strongly disagree as non-parametric tests were not performed due to data limitations" (see Section 2.1 below).

In section seven, a justification statement was formulated to introduce the purpose of this section. The statement was "Some power plants want to utilize municipal wastes to produce electricity and heat. This process reduces waste going to landfill. Would you accept burning the following waste in power plants? The items included MSW, agriculture residues (straw), forest harvesting residues, waste wood from buildings and furniture, and waste from gardening and 
fruit orchards pruning. These are common sources of wastes used for energy generation in Poland. The 5-point Likert scale was used here as in previous sections (strongly agree, agree, I don't know, disagree, and strongly disagree). Scale items were combined as in section five and six. Finally, an open space was left for the participants to freely comment on the questionnaire and on MSW management system in their city. As per data collection, random sampling was performed within $5 \mathrm{~km}$ radius from Wrockaw city center. The area was chosen because of a high population density and the presence of many businesses and entertainment facilities, and where it is easy to approach people of different age groups and backgrounds. Simultaneously, an online tool was developed using Google Forms and distributed to the residents of Wrocław through social media (Facebook). An electronic copy of the questionnaire can be requested from the author via email.

\section{Data Limitations}

Resources and time limitations are typically limiting factors in survey-based studies. Moreover, the collected data appeared, unintentionally, skewed toward young participants representing the majority $(86 \%)$ of the study sample. Therefore, such data type refrained us from using non-parametric statistical analysis such as Chi square or Mann-Whitney to reveal statistical difference in selected independent variables such as age, income and educational level. Nonetheless, the data can provide insights on the public attitudes and perceptions and can assist in quantifying the waste types and share of household recycling.

\section{Results}

\subsection{Bio-Demographics and Socio-Economic Characteristics}

The questionnaire was presented to approximately 200 potential respondents and in total 160 participants filled in the questionnaire with $80 \%$ response rate. Regarding gender, 44 (27.5\%) males and (116) 72.5\% females participated in this study. The majority of the participants $137(85.6 \%)$ lives in flats and the rest lives in terraced houses. Regarding family size, 117 participants (73\%) indicated a family size between one and three (the couple and one kid) and the rest 43 (30\%) have four to seven (the couple and two to five kids). As per the participants age, the majority 126 (79\%) were young (25 - 35-year-old), 16 (10\%) aged between 36 and 45 years old, and the rest $18(11 \%)$ aged 46 years and over. The educational attainment of the participants showed that slightly over half (52\%) of the participants hold a college degree and $44 \%$ finished their high school and currently attending a college degree and $4 \%$ indicated basic education in the old age group. Since the city is vibrant and regarded as a destination for working and studying, $38 \%$ of the participants indicated having living in the city between 1 and 5 years (graduate students), and 39\% living in the city for more than 20 years (senior citizens). Income level appeared a sensitive issue thus many participants chose not to reveal however about $29 \%$ of the participants indicated 2000 to 4000 zloty 
$(1$ euro $=4.26$ Poland złoty $)$.

\subsection{Waste Management Options at the Domestic Level}

This section was a starting point for analyzing waste management options at the domestic level. Here, approximately $74 \%$ (118) of the participants indicated that they possess waste containers and bags at home and 26\% (42) said they don't have. About $54 \%$ of the participants did not know how much fees they pay for waste collection-as it is usually included in the rent however some participants indicated that it is either 0.85 zloty per rented square meter or 12 zloty per person (roughly 3 euros). Almost all the participants indicated that they don't get any sort of incentives for waste separation.

\subsection{What Are the Key Sources of Information?}

As per the relevance of selected information sources, the respondents appeared highly favoring the internet $(86.3 \%)$ followed by the national TV $(27.5 \%)$ followed by radio (26.9\%) (Figure 2). The fact that the majority of the respondents are young makes the results understandable. Young people are increasingly following the internet not only for basic information but also to look for jobs, medical information, news, pay bills and banking, and many other days life uses. National TV is followed on special occasions and events such as elections whilst Radio is mainly followed during driving car toward work thus it can be still a source of news and information besides its entertainment purposes.

The EU TV channels are only followed by $4.4 \%$ due probably to language barrier, particularly among senior citizens.

\subsection{Self-Reported Frequency of Waste Separation at the Household Level}

The participants in this study were asked to self-report the frequency of separating waste at home and for five waste categories as shown in Figure 3. The scale of response varies from regularly, sometimes, and never. As per Figure 3, around $60 \%$ of plastics, papers, and glasses are being separated and about $50 \%$ of metal wastes. Around $20 \%$ of all wastes are "never" separated and $29 \%$ for food waste. Food waste appeared the least separated (34\%). This is probably due to the lack of wastes containers at home thus people tend to simply mix it with other wastes. Moreover, during field inceptions we found no containers for food wastes/biowastes. Therefore, it is rather expected that people do not separate the food waste from others.

\subsection{Quantified Waste Separation at the Household Level}

The self-reported waste separation frequencies were crossed checked with the qauantative waste separation assessment we included in the survey (Figure 4). As indicated both self-reported and the quantified waste separation appeared closely comparable. 


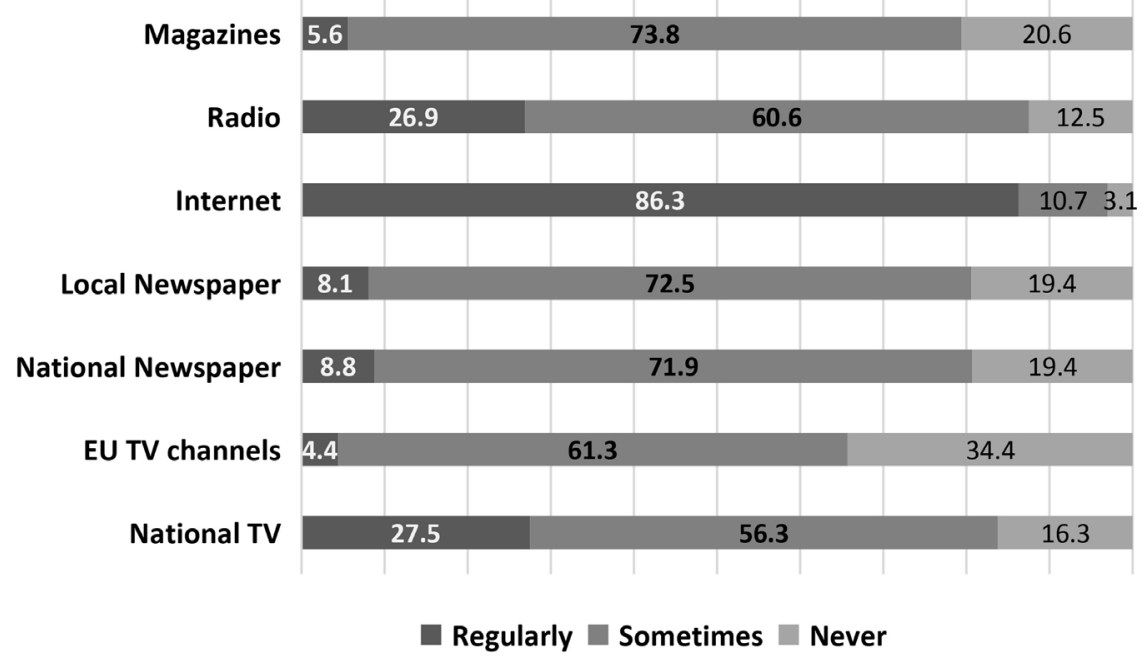

Figure 2. Frequency of following various traditional mass media sources.

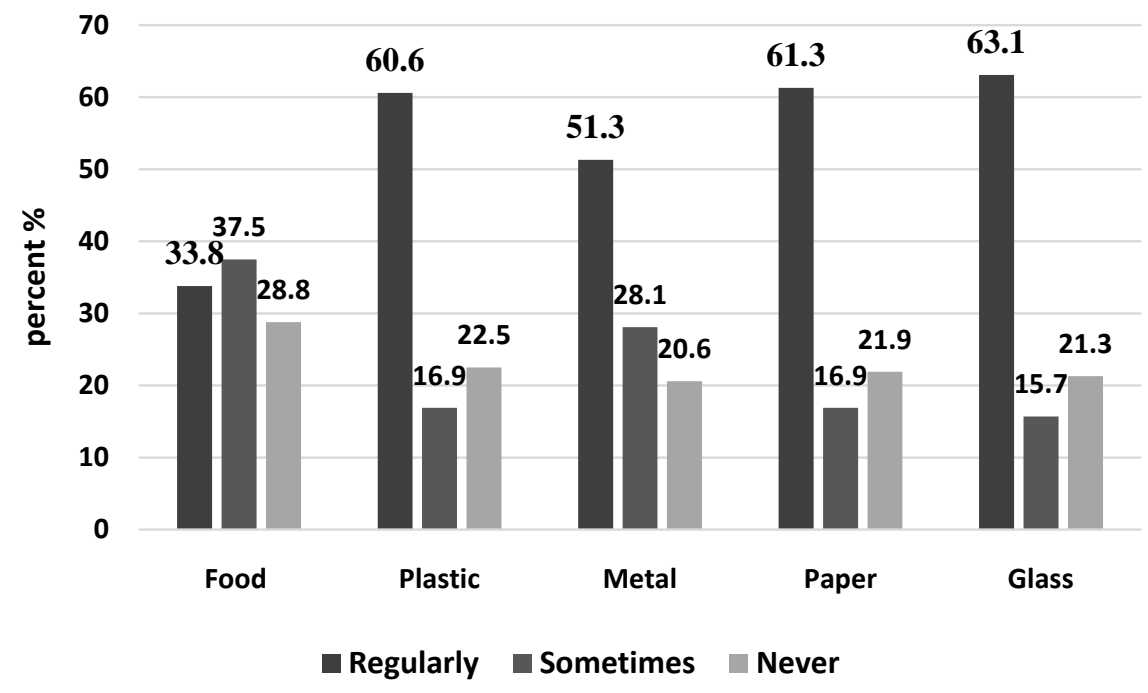

Figure 3. Frequencies of waste separation at the domestic level.

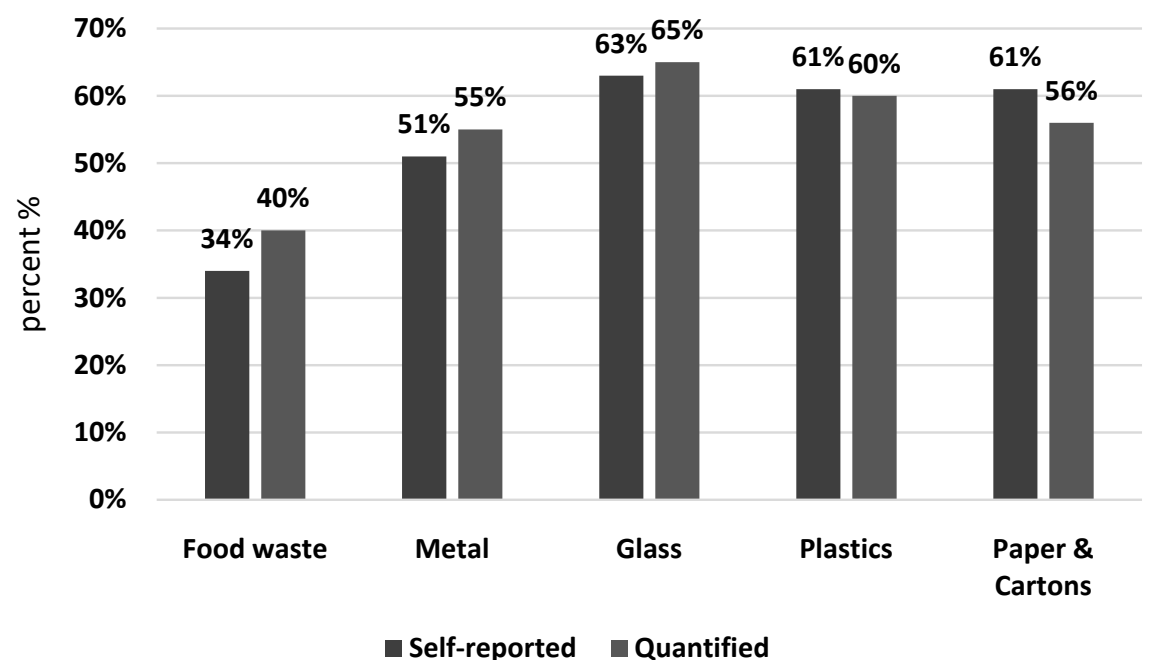

Figure 4. Self-reported vs quantified waste separation at the domestic level. 


\subsection{Perceptions and Attitudes toward MSW Management}

How the participants perceive the benefits of waste management and what is the current situation of MSW in their city was tested through nine statements (Figure 5). The results revealed several noteworthy findings. First, the participants appeared aware of the waste management benefits as $87 \%$ of the participants believe that "waste separation is very important for the cleanliness of the environment in my town" [statement 9] and accordingly 73\% of the participants convey waste management behaviors to their kids [statement 1]. However, the participants appeared unsatisfied about the current waste management system in their city as only $29 \%$ of the participants believe that waste management system is both efficient and sufficient [statement 7 and 8]. Therefore, over two-third of the participants (63\%) believe that "waste management is a societal problem in my town" [statement 5] and thus 68\% strongly believe that "the local government should do more about waste management in my town" [statement 6]. The accession to the EU in 2004 has introduced remarkable infrastructural improvements to Poland however $76 \%$ of the participants still believe that "some European countries have better waste management system than Poland" [statement 3]. A knowledge and awareness gap was identified in statement 2 and 4 . Here, slightly over one-third of the participants said strongly agreed that they "I do not know what happens to the wastes when I separate them" [statement 2]. The commonly held perception probably is that wastes go to landfilling and the participants probably did not know about waste-to-energy concept and energy generation possibilities such as biogas production, plastics recycling and downgrading processes. The other gap was related to waste separation process itself as $52 \%$ of the participants strongly agreed to the statement that "people do not know how to separate wastes" [statement 4]. The key findings in this section indicate that waste management is perceived to have positive societal and environmental impacts however the current waste management infrastructures are not so

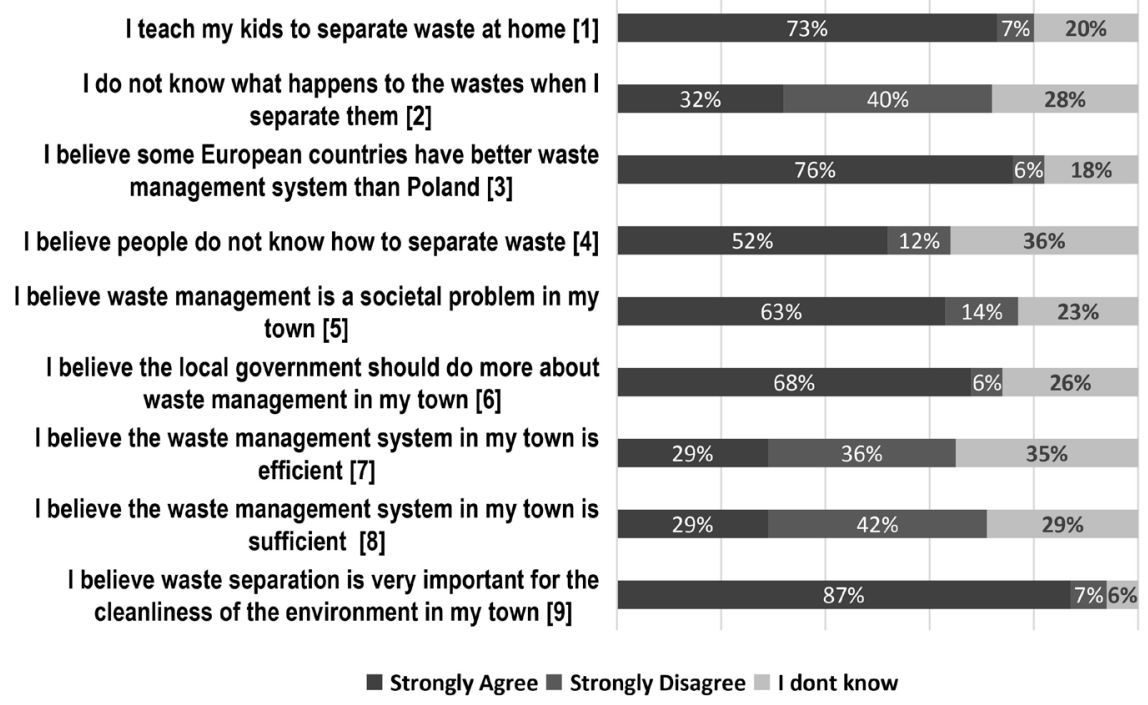

Figure 5. The respondents' perceptions toward the current WM situation in their city. 
satisfying from the participants' point of view. In the next section we discuss what the people need to engage in waste management more proactively.

\subsection{Motives/Incentives for Active Waste Management Behavior(s)}

In this part of the survey study, six items were presented to reveal the respondents' wishes to improve their waste management (Figure 6). As indicated, the respondents acknowledge the need for information about the environmental benefits of waste separation (item 1) and more information on how to separate the wastes (item 2). The need for more fiscal incentives or tax benefits appeared, surprisingly, not on the top of the respondents' wish-list ( $41 \%$ for item 3 ). The need for waste collection containers, particularly close-by home and colored, appeared the most needed waste separation physical infrastructures (item 4 and 5). Finally, almost two third of the respondents wish to have "free" and colored bins and/or bags inside their home to engage in waste separation process.

\subsection{Which Waste Type Can Be Combusted?}

In Poland, biomass is considered renewable energy source, thus, it was substantially utilized as part of the green certificate mechanism and quota obligations to achieve Poland's renewable energy targets [27]. In this process biomass (local and imported) was incinerated with coal in combined heat and power plants. Several power plants however sought to include refuse-derived fuel (RDF) from waste segregation lines and other sources of waste biomass. The objective is ultimately to reduce landfilling and direct incineration of waste, which is publicly sensitive and not fully acceptable. In this regard we asked the respondents which waste type they would accept burning in power plants (Figure 7). Agriculture biomass appeared the most preferable choice as it is rather abundant in Poland followed by forest harvesting residues, although forest harvesting in Poland is not commercially practiced but rather tending activities with residues being sold to public at modest prices. Almost half of the respondents disagreed on burning

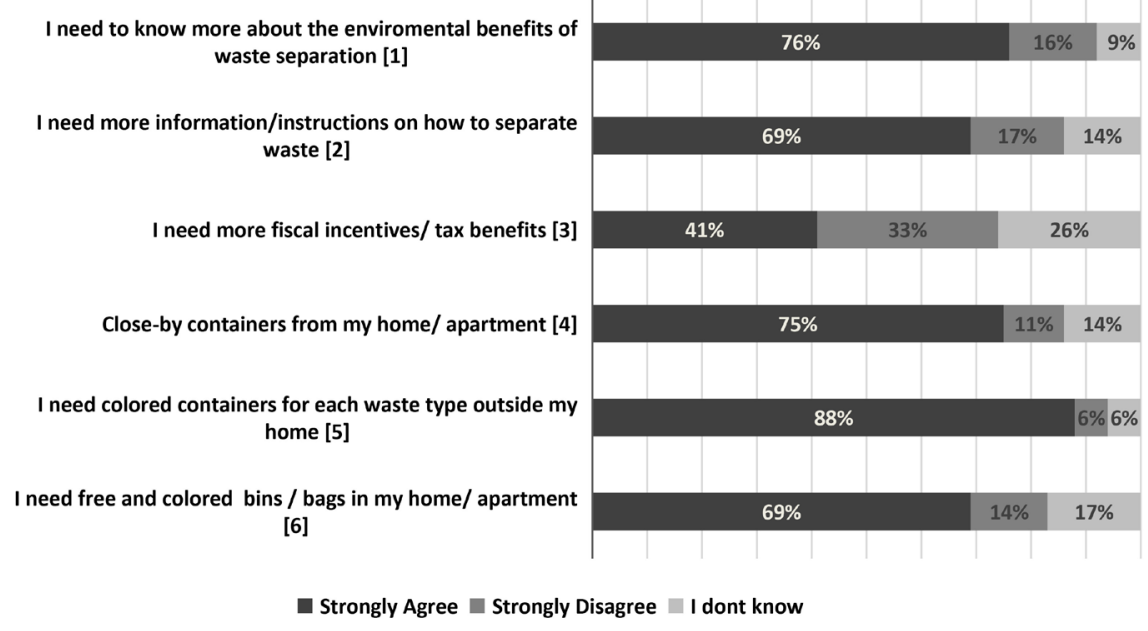

Figure 6. The respondents' wishes to improve their MW behaviors. 


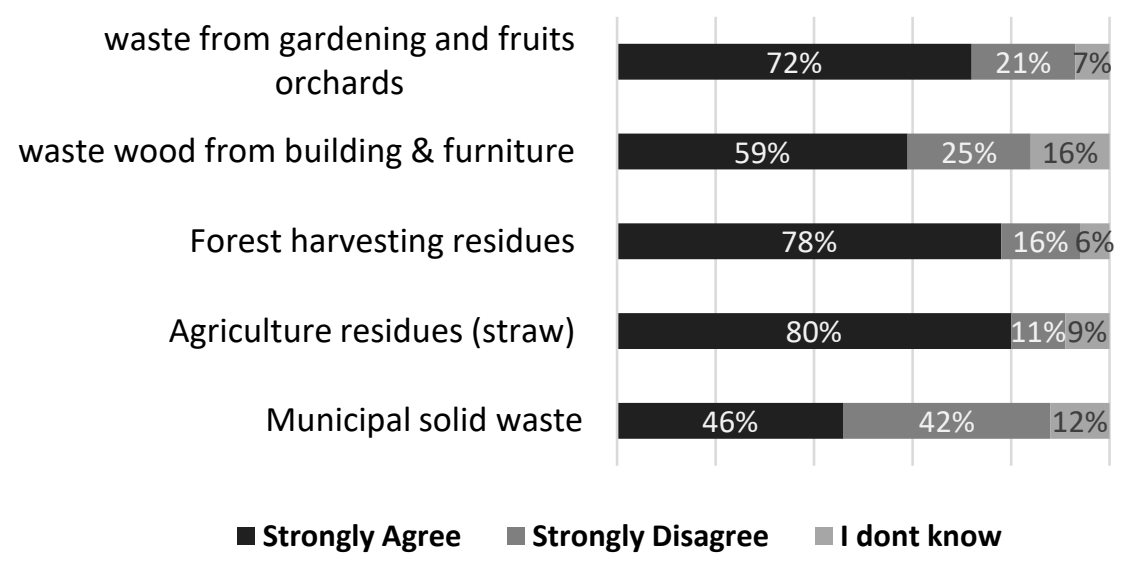

Figure 7. The respondents' preferred choice for waste co-firing in power plants.

MSW in power plants. Before joining the EU, MSW burning in landfill was common practice in Poland therefore the public does not support such notion although it was not clearly explained to the respondents whether it is RDF or direct incineration of wastes.

\subsection{Respondents' Free Expressions of MSW Management}

Waste management is a common developmental and social challenge in many countries around the world. It is inherently related to the availability of waste infrastructures or consumption behaviors and practices. One respondent referred to the problem as typically social "... as long as people do not want to do it or are lazy to do it the problem will continue". Other respondents had different view by referring to the waste infrastructures in the neighbourhood " $I$ would separate waste if I had containers, it is strange that there are only 3 bins for waste separation". Other participant added "the containers should be easier to use (referring to the very heavy lid), they should be more colorful and aesthetic to attract attention". Another respondent brought about the problem of irregularity of waste collection "The bins are often overfilled; the wastes should be collected more frequently". Another noteworthy notes by the respondents revealed the lack of waste-designated containers such as glass containers "We do not have container for glasses, we need to drive it to the appropriate place".

A distinctive challenge in Poland is the relatively small-sized flats in multistory buildings therefore it might be difficult to find space for containers at home as one respondent allude to " $M y$ flat is too small to place any additional trash bins". A rather bizarre comment from one respondent referring to waste collection by waste collection companies "Why should I segregate waste if only one truck takes all the wastes away, especially since I pay more for segregation...? I would definitely change my behavior if I was sure the wastes won't be mixed afterwards'. It seems waste collection vehicles collect and mix waste in one load; therefore, it must be investigated by authorities and waste companies alike. Another respondent has also pinpointed to the same problem " $P$ m mostly not at 
home, my children usually take care of it. They teach me to segregate, but I have seen myself that the wastes from all containers for segregation are put into one truck'. The waste collection fees are fiscal incentives for waste management companies, but it does not offer any incentives for individuals to separate waste. Therefore, one respondent commented "...this fee makes no sense, we should teach people to be more economical if we want to have less waste". Elevating awareness and linking waste separation and less-waste behaviors might bring about wide array of benefits for the individuals and the environment alike. Indeed, people would reduce waste if the gains/benefits are felt in the immediate terms such as money saving, self-respect and comfort rather speculating the long-term benefits on the environment, which people do not easily sense or realize.

\section{Conclusion}

Waste management includes waste prevention, recycling, and segregation whenever possible. The process falls into circular economy strategy with various socio-economic and environmental benefits including, inter alia, income generation and employment, cleaner cities, energy production, and efficient resource utilization. Poland benefited from joining the EU and waste management has tangibly improved. Yet again, the waste management infrastructure and private sector engagement remain a key and pivotal factor in reducing landfilling. Other studies highlighting the need for public support, elevating their awareness and understanding for waste prevention and/or recycling arose from the notion that economic growth will increase the share of people entering the middle-income class; hence, more waste (organic and solid) will be generated. In developing countries, population growth will have a similar effect on waste generation. In this study we realized the respondents' awareness and willingness to engage in waste management; however waste infrastructures need to be further improved. Artificial Intelligence (AI) and industrial ICT solutions will play a key role in advancing waste management globally.

\section{Acknowledgements}

The work was carried out in the Sustainable Bioenergy Solutions for Tomorrow (BEST) research program coordinated by CLIC Innovation with funding from the Finnish Funding Agency for Innovation, Tekes (http://www.clicinnovation.fi). The authors would like to sincerely thank all the participants in this survey study. The study was also funded by CONVER-B project (Academy of Finland) and the Karelia CBC Programme 2014-2020 funded project "Reaching congenial region through valorization of municipal and industrial waste waters and sludge" KA4020.

\section{Conflicts of Interest}

The authors declare no conflict of interests with other parties. 


\section{References}

[1] Welivita, I., Wattage, P. and Gunawardena, P. (2015) Review of Household Solid Waste Charges for Developing Countries-A Focus on Quantity-Based Charge Methods. Waste Management, 46, 637-645. https://doi.org/10.1016/j.wasman.2015.08.018

[2] Commission for Environmental Cooperation (CEC) (2017) Characterization and Management of Organic Waste in North America-White Paper. Commission for Environmental Cooperation, Montreal, Canada, 48.

[3] Annepu, R.K. (2012) Sustainable Solid Waste Management in India. Waste-to-Energy Research and Technology Council (WTERT), Columbia University, New York.

[4] Wang, S.W., Wen, X.N. and Qin, L. (2014) Model Construction of Municipal Solid Waste Management with Public Participation and Government Regulation Interactive in China. China Population Resources and Environment, 24, 142-148.

[5] Euro Statistics (2018) Municipal Waste Statistics. https://ec.europa.eu/eurostat/statistics-explained/index.php/Municipal waste statis $\underline{\text { tics }}$

[6] Cimpan, C., Maul, A., Jansen, M., Pretz T. and Wenzel H. (2015) Central Sorting and Recovery of MSW Recyclable Materials: A Review of Technological State-of-the-Art, Cases, Practice and Implications for Materials Recycling. Journal of Environmental Management, 156, 181-199. https://doi.org/10.1016/j.jenvman.2015.03.025

[7] Parizeau, K., Massow, M.V. and Martin, R. (2015) Household-Level Dynamics of Food Waste Production and Related Beliefs, Attitudes, and Behaviours in Guelph, Ontario. Waste Management, 35, 207-217. https://doi.org/10.1016/j.wasman.2014.09.019

[8] Wustenhagena, R., Wolsink, M. and Burer, M.J. (2007) Social Acceptance of Renewable Energy Innovation: An Introduction to the Concept. Energy Policy, 35, 2683-2691. https://doi.org/10.1016/j.enpol.2006.12.001

[9] Assef, G. and Frostell, B. (2007) Social Sustainability and Social Acceptance in Technology Assessment: A Case Study of Energy Technologies. Technology in Society, 29, 63-78. https://doi.org/10.1016/j.techsoc.2006.10.007

[10] Yuan, X., Zuo, J. and Ma, C.Y. (2011) Social Acceptance of Solar Energy Technologies in China-End Users' Perspective. Energy Policy, 39, 1031-1036.

https://doi.org/10.1016/j.enpol.2011.01.003

[11] Cohen, J., Reich, J. and Schmidthaler, M. (2014) Re-Focusing Research Efforts on the Public Acceptance of Energy Infrastructure: A Critical Review. Energy, 67, 4-9. https://doi.org/10.1016/j.energy.2013.12.056

[12] Stigka, E.K., Paravantis, J. and Mihalakakou, G.K. (2014) Social Acceptance of Renewable Energy Sources: A Review of Contingent Valuation Applications. Renewable and Sustainable Energy Reviews, 32, 100-106.

https://doi.org/10.1016/j.rser.2013.12.026

[13] Kandpal, T.C. and Broman, L. (2014) Renewable Energy Education: A Global Status Review. Renewable and Sustainable Energy Reviews, 34, 300-324. https://doi.org/10.1016/j.rser.2014.02.039

[14] Martinsson, J., Lundqvist, L.J. and Sundström, A. (2011) Energy Saving in Swedish Households. The (Relative) Importance of Environmental Attitudes. Energy Policy, 39, 5182-5191. https://doi.org/10.1016/j.enpol.2011.05.046 
[15] Edjabou, M.E., Petersen, C., Scheutz, C. and Astrup, T.F. (2016) Food Waste from Danish Households: Generation and Composition. Waste Management, 52, 256-268. https://doi.org/10.1016/j.wasman.2016.03.032

[16] Zyadin, A., Puhakka, A., Halder, P., Ahponen, P. and Pelkonen, P. (2014) The Relative Importance of Home, School, and Traditional Mass Media Sources in Elevating Youth Energy Awareness. Applied Energy, 114, 409-416. https://doi.org/10.1016/j.apenergy.2013.09.072

[17] Secondi, L., Principato, L. and Laureti, T. (2015) Household Food Waste Behaviour in EU-27 Countries: A Multilevel Analysis. Food Policy, 56, 25-40. https://doi.org/10.1016/j.foodpol.2015.07.007

[18] Afroz, R., Tudin, R., Hanaki, K. and Masud, M.M. (2011) Selected Socio-Economic Factors Affecting the Willingness to Minimise Solid Waste in Dhaka City, Bangladesh. Journal of Environmental Planning and Management, 54, 711-731. https://doi.org/10.1080/09640568.2010.527472

[19] Sangodoyin, A.Y. and Ipadeola, S.F. (2000) Hazardous Wastes: Assessing the Efficacy of Structures and Approaches to Management in Nigeria. Environmental Management and Health, 11, 39-46. https://doi.org/10.1108/09566160010314170

[20] Nilanthi, J.G.J.B., Hettiaratchi, P.A.J., Wirasinghe, S.C. and Pilapiiya, S. (2007) Relation of Waste Generation and Composition to Socio-Economic Factors: A Case Study. Journal of Environmental Monitoring Assessment, 135, 31-39. https://doi.org/10.1007/s10661-007-9705-3

[21] Nuzrath, A.N.N. and Ruzaik, F. (2017) Public Perceptions on Effectiveness of Solid Waste Management in Colombo Municipality Area. Technical Report.

[22] Bom, B.U., Shashidhar Belbase, S. and Lila, R.B. (2017) Public Perceptions and Practices of Solid Waste Recycling in the City of Laramie in Wyoming, U.S.A. Recycling, 2, 1-19. https://doi.org/10.3390/recycling2030011

[23] Meneses, G.D. and Palacio, A.B. (2005) Recycling Behavior: A Multidimensional Approach. Environment and Behavior, 37, 837-860. https://doi.org/10.1177/0013916505276742

[24] Sidique, S.F., Lupi, F. and Joshi, S.V. (2010) The Effects of Behavior and Attitudes on Drop-off Recycling Activities. Resources, Conservation \& Recycling, 54, 163-170. https://doi.org/10.1016/j.resconrec.2009.07.012

[25] Fischer, C. (2012) Municipal Waste Management in Poland. Working Paper for the European Environment Agency (EEA) under Its 2012 Work Programme. Copenhagen Resource Institute. http://www.cri.dk/

[26] National Waste Prevention Programme of Poland (2015). http://www.mos.gov.pl/g2/big/2014 10/a400f6bb998e8fbc1bc8451fe5c41b11.pdf

[27] Zyadin, A., Natarajan, K., Igliński, B., Iglińska, Kaczmarek, A., Kajdanek, J., Trishkin, M., Lisowski, A., Dąbrowska, M., Pelkonen, P. and Pappinen, A. (2019) Farmers' Perceptions of the Challenges Facing the Biomass Market in Poland; A Case Study from South and Central Poland. Biofuels, 1-9. https://doi.org/10.1080/17597269.2018.1546486 